\title{
Comunicación

\section{Las marcas de la profesionalización avanzada: un acercamiento descriptivo a las tesis de maestría en comunicación del ITESO y de la UdeG a través de sus referentes bibliográficos}

RAÚl FUENTES NAVARRO*

En este artículo, avance de un proyecto de investigación de alcance más amplio, se presentan los resultados de un primer acercamiento descriptivo a los productos formales (tesis de grado) de los programas de maestría en comunicación del ITESO y la Universidad de Guadalajara, realizado mediante un análisis de los referentes bibliográficos que contienen. En este nivel se enfatizan las similitudes encontradas en los "perfiles de referencias" de las tesis de ambas instituciones y la relativamente alta proporción de citas a productos de la investigación mexicana, sobre todo los producidos por profesores de las mismas maestrías.

PALABRAS CLAVE: campo académico de la comunicación / tesis de posgrado / análisis descriptivo /bibliografía / bibliometría.
As an advance of a broader research project, this article displays the results of a preliminary descriptive approach to the master's degrees theses presented at ITESO and the University of Guadalajara, oriented by the analysis of the bibliographies contained in the theses. Some findings are emphasized: there are similarities between the "reference profiles" constructed for the two programs, and a shared relatively high proportion of references to Mexican research products, especially those whose authors are members of the faculties of the same programs.

KEY WORDS: academic field of communication / theses and dissertations / descriptive analysis /bibliography / bibliometrics

* ITESO / Universidad de Guadalajara.

Correo electrónico: raul@iteso.mx 
En el contexto de la reestructuración constante de las instancias de producción académica, tanto en lo que respecta a las condiciones de la investigación científica como a las de la educación superior (y su articulación más directa: la formación de investigadores en los posgrados), sujetas a una doble dinámica de cambio (por un lado el mercado, y por otro las políticas públicas), que exige mayor "eficiencia y productividad", es indispensable el autoreconocimiento de las condiciones de desarrollo de los campos especializados, para dar mayor sustento y solidez a su evaluación y para contar con mejores recursos intelectuales para la toma de decisiones de reorientación o reforzamiento de tendencias. En el caso de los estudios sobre la comunicación, parece especialmente conveniente considerar articuladamente las dimensiones de institucionalización (social y cognitiva), profesionalización (básica y avanzada) y legitimación (académica y social) del campo académico (Fuentes, 1998), lo cual implica, en otros términos, su "identidad":

Esa cuestión de la identidad o la autonomía de la comunicación en cuanto campo -o sobre sus interfases con otras disciplinas- es siempre actual, en un área considerada nueva y multidisciplinaria. Hay quien propone que no se considere a la comunicación como una ciencia o una disciplina, dado que no tiene principios explicativos propios, siguiendo modelos teóricos prestados de otras disciplinas. Hay también aquellos que aceptan la existencia de una disciplina llamada comunicación, si bien señalan su ausencia de autonomía como campo de conocimiento (Capparelli y Stumpf, 2001: 63-64).

Por ello también es clara la conveniencia de sustentar en el análisis empírico sistemático la apreciación de las condiciones y tendencias de desarrollo de los campos académicos que, como espacios sociales para múltiples prácticas y proyectos divergentes, suelen estar más determinados por factores de poder extraacadémico que por la propia racionalidad académica y científica (Bourdieu, 1988, 2000). Los programas de posgrado (maestría y doctorado) son sin duda instancias privilegiadas de reproducción de los campos académicos, mediante la "profesionalización avanzada", cuyas condiciones de desarrollo son sin embargo insuficientemente conocidas, al menos en México y, para el caso, en la comunicación. 
En este trabajo se presentan los resultados de un primer acercamiento descriptivo a los productos formales (tesis de grado) de los programas de maestría en comunicación del ITESO y la Universidad de Guadalajara, realizado mediante un análisis de los referentes bibliográficos que contienen. Se ha decidido centrar el análisis en las tesis de posgrado a partir del supuesto de que, por su propio carácter, en ellas se explicitan las fuentes bibliográficas y los procedimientos metódicos de una manera más rigurosa que en otros productos de la investigación académica, además de que representan la instancia fundamental de objetivación de los procesos de reproducción y renovación de un campo académico ${ }^{1}$. Se busca, especialmente, observar las correspondencias que pueda haber entre la definición institucional de especialidades de investigación y la referencia a "cuerpos" de conocimiento objetivados bibliográficamente ( $\mathrm{y}$, a través de esta objetivación, a distinciones epistemológicas, teóricas y metodológicas), así como a los propósitos de la formación de posgraduados. De esta manera, hipotéticamente, podrá disponerse de mejores elementos de reconocimiento de las pautas concretas de constitución "disciplinaria" o "transdisciplinaria" de los estudios sobre la comunicación en estas instituciones, que se cuentan entre las más influyentes del campo académico nacional y latinoamericano (Fuentes, 2003).

\section{ANTECEDENTES Y ENTORNO DEL ESTUDIO}

En el doble contexto de un proyecto de desarrollo de bases de información titulado La investigación académica sobre comunicación en México 1950-20002, cuyo principal producto es la biblioteca virtual $c c d o c$

1 Aunque, obviamente, la información generada en el análisis de las tesis deberá ser "cruzada" con información proveniente de análisis de otras fuentes (libros, revistas, programas) para poder ser debidamente interpretada y contextualizada.

2 Realizado entre 2001 y 2004 en el Departamento de Estudios Socioculturales del ITESO bajo la responsabilidad de Raúl Fuentes Navarro, con el apoyo de la Biblioteca "Dr. Jorge Villalobos Padilla S.J." y del Consejo Nacional de Ciencia y Tecnología (CONACyT) (R-34247 S), con el objetivo 
[http://ccdoc.iteso.mx], y su proceso de formación en la maestría en comunicación con especialidad en difusión de la ciencia y la cultura del ITESO, Gabriela de la Torre (2003) realizó hace pocos años un análisis descriptivo de las tesis de maestría presentadas en tres programas nacionales entre 1996 y 2000, "con el objetivo de identificar los rasgos distintivos de la producción de conocimiento y la formación de nuevos agentes dentro del campo académico de la comunicación en México" (De la Torre, 2004: 85). En ese trabajo se analizaron 126 tesis, 40 presentadas en la UNAM, 42 en la Universidad Iberoamericana y 44 en el ITESM. Uno de los criterios fundamentales fue que los programas contaran con el reconocimiento del Padrón de Posgrados de Excelencia de CONACyT, ahora denominado Padrón Nacional de Posgrado. Al perfilar el proyecto, en 2001,

No se consideraron otros programas inscritos en el padrón (como las maestrías de la UAM-Xochimilco, la Universidad de Guadalajara o el ITESO) sobre todo porque debido a su más reciente fundación, no han producido aún tesis en un número mínimamente considerable; ni otros programas, cuyos objetivos de formación los alejan de los parámetros de la investigación, o que, sea por su orientación o por el tiempo transcurrido, tampoco han generado un conjunto de tesis evaluable como tal (De la Torre y Fuentes, 2002: 260).

Este primer acercamiento sistemático al análisis de las tesis de maestría en comunicación producidas en México, aportó datos interesantes y en algún sentido intrigantes, al relacionar sus hallazgos, por un lado, con los perfiles de egreso de los programas (formación de docentes, de profesionales especializados y/o de investigadores), y, por otro, con la influencia de los profesores-investigadores que, como asesores o directores de las tesis, en alguna medida inducen en los estudiantes de posgrado sus propias tendencias de investigación. "Aunque las tesis

general de "consolidar una base de datos bibliográficos lo más completa, actualizada y orientada a los usuarios que sea posible, sobre la producción científica mexicana en el campo académico de la comunicación y ponerla a disposición de la consulta pública mediante la tecnología informática más avanzada”. 
abordan múltiples temas y objetos de estudio, desde distintos enfoques, es posible identificar ciertas tendencias temáticas, de objetos de estudio y de metodologías empleadas" (De la Torre, 2004: 123). Pero también se señala que:

se pueden encontrar ciertos consensos construidos dentro de las universidades y concretados en las líneas de investigación de las maestrías, en cuanto a la definición de un objeto de estudio específico y una mirada que distingue las ciencias de la comunicación de otras disciplinas sociales. Las diferencias entre las tesis de las tres universidades responden, en este sentido, al perfil de cada maestría, las líneas de investigación propuestas y los profesores que laboran en cada programa (idem).

Un proyecto de investigación posterior (Bustamante, 2004), también encuadrado como tesis de maestría pero con un enfoque distinto (ofertas institucionales del nivel de posgrado) y un alcance geográfico mayor (Latinoamérica), permite contextualizar el crecimiento explosivo del número de programas de posgrado en comunicación a partir de los años 90 y los diversos factores de la institucionalización del campo académico. "La acreditación, como parte de una 'cultura de la evaluación' dentro de los sistemas de educación latinoamericanos, es una tendencia inevitable y se ha convertido en un sello para distinguir entre posgrados de primera y segunda categoría" (Bustamante, 2006: 162). Desde esta perspectiva, la propia denominación de los programas está fuertemente asociada con la legitimación institucional, pero también con las perspectivas de desarrollo propiamente académico que ofrecen los posgrados "en comunicación":

... se va produciendo una dispersión temática: cada vez más programas van ampliando los objetos de estudio para la comunicación, ya sea mediante recortes específicos (comunicación-cultura, comunicación-tecnologías educativas, comunicación-política), ya sea mediante la integración con otras disciplinas y temáticas (semiótica, publicidad, salud, multimedios). A la luz de esta dispersión temática, coincidente con la irrupción de la oferta en los años 90, se aprecia mejor la formulación de los programas en términos de sus perfiles de ingreso y egreso. (ibid.: 163). 
Tanto el estudio de De la Torre como el de Bustamante advierten que, al analizar los programas de posgrado en comunicación, están enfrentando un objeto móvil, sujeto a cambios muy rápidos, pero aparentemente generalizados, cuya descripción implica un sentido heurístico que articule estas instancias fundamentales del campo académico de la comunicación con los factores internos y externos que hipotéticamente los están determinando. En esa misma línea se puede ubicar el proyecto de investigación ${ }^{3}$ en el cual se encuadra, como una primera fase de exploración descriptiva, este análisis de los referentes bibliográficos de 71 tesis de maestría en comunicación, presentadas en años recientes en la Universidad de Guadalajara y el ITESO.

Formalmente, ambos programas de posgrado iniciaron su operación a mediados de 1998 y están reconocidos con la categoría de "alto nivel" en el Padrón Nacional de Posgrado, aunque en los dos casos hay antecedentes directos, que al menos desde el punto de vista de la perspectiva analítica adoptada aquí, permiten ampliar el corpus al reconocer la continuidad académica que se ha dado en ambas instituciones. El ITESO abrió una primera versión de su programa de maestría en 1985, y en él obtuvieron su grado algunos de los profesores que, habiendo acreditado también su doctorado, forman parte de las plantas académicas del propio ITESO y de la Universidad de Guada-

3 Este proyecto, titulado La constitución científica del campo académico de la comunicación en México y en Brasil: análisis comparativo, tiene un plazo de realización de tres años (2005-2008) y apoyo del Consejo Nacional de ciencia y Tecnología (CONACyT) $(47377$ H). Su objetivo general es "analizar comparativamente la constitución de redes científicas y núcleos de especialización, mediante la identificación de convergencias temático-referenciales y teórico-metodológicas en las tesis de posgrado, en el contexto de los procesos de institucionalización, profesionalización y legitimación del campo académico de la comunicación en México y en Brasil”. Por la parte mexicana, incluye el análisis de las tesis de maestría en comunicación y de doctorado con esa temática de cinco universidades: la UNAM, la Universidad Iberoamericana, el ITESM, el ITESO y la Universidad de Guadalajara, presentadas entre 1996 y 2005. 
lajara 4 que sostienen los programas actuales. Por razones diversas, ese programa debió ser cerrado en 1992, aunque explícitamente se recuperó la experiencia acumulada en el "nuevo" programa abierto en 1998 por el Departamento de Estudios Socioculturales. Por su parte, la maestría de la Universidad de Guadalajara fue planeada y aprobada en 1993, aunque no fue abierta sino hasta 1998. La decisión institucional, en este caso, fue incorporar el posgrado en comunicación como una especialidad de la Maestría en Ciencias Sociales, abierta en 1994 como un programa interdepartamental del Centro Universitario de Ciencias Sociales y Humanidades. A la fecha, esta especialidad (en Comunicación Social) sigue vigente, también con la categoría de “alto nivel" en el Padrón Nacional de Posgrado, atendida simultáneamente a la maestría en comunicación por el personal académico del Departamento de Estudios de la Comunicación Social5.

El total de 71 tesis de maestría analizadas incluye, entonces, cuatro realizadas en la primera etapa del programa del ITESO y 26 en la actual; 14 presentadas en la maestría en ciencias sociales y 27 en la de comunicación de la Universidad de Guadalajara. En el anexo se presentan los datos completos de las 71 tesis analizadas.

4 Son los casos de Raúl Fuentes, Ramiro Caballero, Rossana Reguillo, Cecilia Cervantes y Renée de la Torre, que obtuvieron en el ITESO sus grados de maestría en comunicación, y después el doctorado en ciencias sociales mediante el programa conjunto de la Universidad de Guadalajara y el CIESAS- Occidente.

5 Los procesos de reestructuración institucional realizados en los años 90 en ambas universidades, sin duda tuvieron que ver con la historia de los respectivos posgrados: en el ITESO la maestría en comunicación nació adscrita a la División de Posgrados, que fue disuelta en 1992, organizacionalmente independiente de la Escuela de Ciencias de la Comunicación, creada en 1967; su sede actual es el Departamento de Estudios Socioculturales, constituido en 1996. En la Universidad de Guadalajara, la maestría en comunicación está adscrita al Departamento de Estudios de la Comunicación Social, constituido en 1994 a partir del antiguo Centro de Estudios de la Información y la Comunicación, fundado en 1986. 


\section{UNA DESCRIPCIÓN FORMAL}

DE LAS TESIS ANALIZADAS

Algunos datos generales pueden ser útiles para ubicar a las tesis analizadas y a sus autores. Como se ha documentado para otros casos y lo permite el perfil de ingreso de las maestrías del ITESO y la Universidad de Guadalajara, es amplia la diversidad de origen de los estudiantes, tanto geográfica como profesionalmente. En ambos casos, entre un tercio y la mitad de los graduados llegaron a estos programas de maestría provenientes de otros estados del país o de otras naciones latinoamericanas, a donde en muchos casos regresaron al terminar el programa. También, aproximadamente la mitad de los graduados contaba al ingresar a la maestría con títulos de licenciatura y/o experiencia profesional diversa a la comunicación. Por género, en las dos universidades predominan las mujeres (57\% en el ITESO y $68 \%$ en la Universidad de Guadalajara, para un $63 \%$ combinado). En cuanto a la edad al ingresar a la maestría, hay amplias diferencias, sobre todo en el ITESO, donde el perfil de egreso "mixto" del programa (formación en investigación y especialización profesional) es más acusado que en la Universidad de Guadalajara, por lo que atrae a más profesionales con experiencia y menores expectativas de continuar después un doctorado. Sin embargo, es equivalente la proporción de egresados de una y otra institución que han seguido este camino de continuidad en la formación como investigadores.

Hay que tomar en cuenta que los programas de maestría en comunicación de donde proviene casi $80 \%$ de las tesis analizadas aquí iniciaron apenas en 1998, y sus primeros titulados presentaron sus tesis a partir de 2002, es decir, en los últimos tres años considerados 6 . De ahí que la distribución del corpus por fechas presente inevitablemente severas

6 En 2006 concluyeron sus tesis y presentaron sus exámenes de grado otros egresados de estas maestrías, pero estos productos no fueron considerados en razón de que el proyecto general estableció un periodo de diez años (1996-2005) para el análisis, y en las tres instituciones restantes (UIA, UNAM e ITESM) comenzaron antes a presentarse tesis de maestría, además de haber mayor dificultad para conseguir los documentos oportunamente que en el ITESO y la Universidad de Guadalajara. 
disparidades por año de presentación de las tesis, con $87 \%$ concentrado en los últimos cuatro años (ver tabla 1).

TABLA 1

TESIS ANALIZADAS POR AÑO DE PRESENTACIÓN

\begin{tabular}{cccc} 
& ITESO $=30$ & UdeG $=41$ & Total $=71$ \\
\hline 1996 & 0 & 0 & 0 \\
1997 & 1 & 0 & 1 \\
1998 & 0 & 3 & 3 \\
1999 & 2 & 0 & 2 \\
2000 & 0 & 1 & 1 \\
2001 & 0 & 3 & 3 \\
2002 & 2 & 7 & 9 \\
2003 & 7 & 10 & 17 \\
2004 & 10 & 14 & 24 \\
2005 & 8 & 3 & 11 \\
\hline
\end{tabular}

En cuanto a la extensión de los trabajos, el promedio de páginas de las tesis del ITESO es de 171, mientras que en la Universidad de Guadalajara es de 198. Sólo una de las tesis tiene menos de 100 páginas, y una más de 300. La bibliografía presenta mayores rangos de variación, aunque el promedio de referencias es prácticamente igual en las dos universidades: las tesis del ITESO contienen en promedio 82.2 referencias, mientras que las de la Universidad de Guadalajara 81.7. El máximo número de referencias en una tesis es 199, y el mínimo 24. Hay que hacer notar que en el procedimiento seguido para elaborar las bases de datos de las referencias bibliográficas de las tesis se detectaron, en prácticamente la totalidad de ellas, deficiencias de leves a medianas en cuanto a la corrección y consistencia de los sistemas de referencias (si bien predominan "versiones" aproximadas del sistema de la American Psychological Association, APA), y se sospecha, aunque no se verificó, que en el cuerpo de las tesis se citan textos cuya referencia no se anota en la bibliografía.

El procedimiento seguido para la captura de la información fue el siguiente: la sección bibliográfica de todas las tesis fue capturada en 
archivos digitales (sea a partir de la digitalización de los ejemplares disponibles en papel o de la conversión de archivos digitales), uno por cada tesis. Todas las referencias de todos los archivos así obtenidos se reformatearon, de manera que cada referencia quedara dividida en cuatro "campos": A) autor y fecha; B) título; C) medio de publicación (revista, libro, sitio web...); y D) lugar de publicación y editorial, (con los ajustes necesarios, dentro de esos cuatro campos, para los distintos tipos de documentos referidos). Las tablas así formadas fueron transferidas a hojas de MS Excel, donde se agregó un quinto "campo": E) clave de identificación de la tesis de donde provenía cada referencia. Luego, todas las referencias fueron integradas en una sola tabla (hoja de cálculo) por institución, donde se homogeneizaron las referencias en cuanto a sus datos (por ejemplo, la fecha de la edición más antigua de un libro o el nombre completo del autor), y se obtuvieron de ese modo las frecuencias de aparición de cada referencia, sin perder la identificación de las tesis individuales ${ }^{7}$. Sólo se eliminaron en este paso las referencias a fuentes no-secundarias que algunas tesis contenían (incorrectamente, por ejemplo, a entrevistas u otras fuentes primarias de información). Finalmente, se clasificaron las referencias según el formato de publicación, en siete modalidades: 1) libros, 2) capítulos, 3) artículos académicos, 4) tesis, 5) documentos impresos y electrónicos, 6) materiales periodísticos, y 7) ponencias o conferencias académicas. También se identificaron, por su origen, las referencias en tres grupos: a) mexicanas, b) iberoamericanas, y c) "extranjeras". Con esta información se elaboró un "perfil de referencias" para cada una de las institu-

7 A partir de este formato, en una fase posterior del proyecto general, se realizarán análisis estadísticos de cocitación para detectar indicadores de la constitución de redes científicas y núcleos de especialización en el campo académico, utilizando las técnicas de investigación, de base cuantitativa, internacionalmente empleadas para objetivar los procesos de constitución de comunidades y especialidades científicas, por la disciplina llamada cienciometría (Callon et al., 1995) o más en general, por los especialistas en bibliotecología o ciencias de la información (Gorbea, 2005), aunque con las reservas anotadas por Hicks (2004) y Campanario (2003), entre otros, para estudios en ciencias sociales. 
ciones, y uno combinado a partir de las referencias presentes en las tesis de ambas universidades. Los resultados de este análisis descriptivo se exponen a continuación.

\section{LOS PERFILES DE REFERENCIAS}

DE LAS TESIS DE MAESTRÍA ANALIZADAS

El primer resultado del análisis efectuado no es en absoluto sorprendente: tanto en el ITESO como en la Universidad de Guadalajara la mitad o un poco más de las referencias utilizadas como fuentes secundarias en las tesis de maestría en comunicación son a libros, mientras que sólo $13 \%$ en el ITESO y $17 \%$ en la Universidad de Guadalajara son a artículos de revistas académicas; es decir, hay una proporción de entre 1:3 y 1:4 en las referencias a artículos y libros. A diferencia de las disciplinas científico-naturales, las ciencias sociales y humanidades, se presenta en todo el mundo este tipo de patrón, especialmente en las sociologías. En tanto medios de comunicación académica, los libros, a diferencia de las revistas, tienen un carácter predominantemente transdisciplinario, como lo han demostrado diversos análisis bibliométricos internacionales, y las implicaciones de esta característica están aún por explorarse en los análisis cuantitativos y cualitativos de estos campos académicos (Hicks, 2004: 6-8).

En la tabla 2 se resumen los perfiles de referencias encontrados en las tesis de maestría en comunicación del ITESO y la Universidad de Guadalajara, según los formatos de publicación de sus fuentes secundarias. Sobra decir que ambos perfiles son muy similares, y queda por saberse si en las maestrías de otras universidades mexicanas se encuentra también este grado de coincidencia, para elaborar interpretaciones más sólidas y de más amplio alcance al respecto.

En el conjunto de las tesis de la Universidad de Guadalajara se encontraron 3351 referencias, por 2466 en las del ITESO, aunque cabe recordar que los promedios por tesis son prácticamente iguales $(81.7 \mathrm{y}$ 82.2 , respectivamente). Al integrar las referencias por universidad buscando las frecuencias de aparición, en la Universidad de Guadalajara se encontraron 304 referencias presentes en dos o más tesis, y en el ITESO 214. Al combinar las dos listas, se encontraron 243 referencias presen- 


\section{TABLA 2}

PERFILES DE REFERENCIAS DE LAS TESIS DE MAESTRÍA ANALIZADAS, SEGÚN FORMATOS DE PUBLICACIÓN

\begin{tabular}{lccc} 
& ITESO & UdeG & Combinado \\
\hline 1) Libros & $50 \%$ & $54 \%$ & $53 \%$ \\
2) Capítulos & $15 \%$ & $16 \%$ & $15 \%$ \\
3) Artículos académicos & $13 \%$ & $17 \%$ & $15 \%$ \\
4) Tesis & $1 \%$ & $2 \%$ & $2 \%$ \\
5) Documentos inéditos & $16 \%$ & $7 \%$ & $11 \%$ \\
6) Material periodístico & $3 \%$ & $3 \%$ & $3 \%$ \\
7) Ponencias no publicadas & $2 \%$ & $1 \%$ & $1 \%$ \\
\hline
\end{tabular}

tes al menos en una tesis de cada universidad (187 libros, 31 capítulos, 24 artículos y una tesis). Con una frecuencia igual o mayor a cinco, hay 46 referencias en las tesis de la Universidad de Guadalajara y 32 en las del ITESO, mientras que en la lista combinada hay 73 textos. En la tabla 3 se recuperan las referencias con frecuencias mayores a $20 \%$ de las tesis en las tres listas.

Como puede observarse, tanto en la Universidad de Guadalajara como en el ITESO hay 16 referencias presentes en $20 \%$ o más de las tesis, siete de las cuales están presentes en ambas listas. Se trata de dos obras fundamentales en la teoría social contemporánea (La construcción social de la realidad, de Berger y Luckmann y La constitución de la sociedad, de Anthony Giddens); de tres libros que articulan el estudio de los medios de difusión en el marco de la teoría social (Ideología y cultura moderna y Los media y la modernidad, de John B. Thompson, y La semiótica social de la comunicación de masas, de Klaus Bruhn Jensen); de la obra monumental en tres volúmenes de Manuel Castells, La era de la información. Economía, sociedad y cultura, y de Culturas híbridas de Néstor García Canclini, único libro de origen mexicano en este conjunto.

Pero entre las 25 referencias más frecuentes en las tesis, sumando (sin combinar) las anotadas en la tabla 3 para las maestrías del ITESO y la Universidad de Guadalajara, hay otras seis obras de autores mexicanos, además de la de García Canclini (dos libros de Guillermo Orozco y uno de Enrique Sánchez Ruiz, uno de María Elena Hernández, uno de 


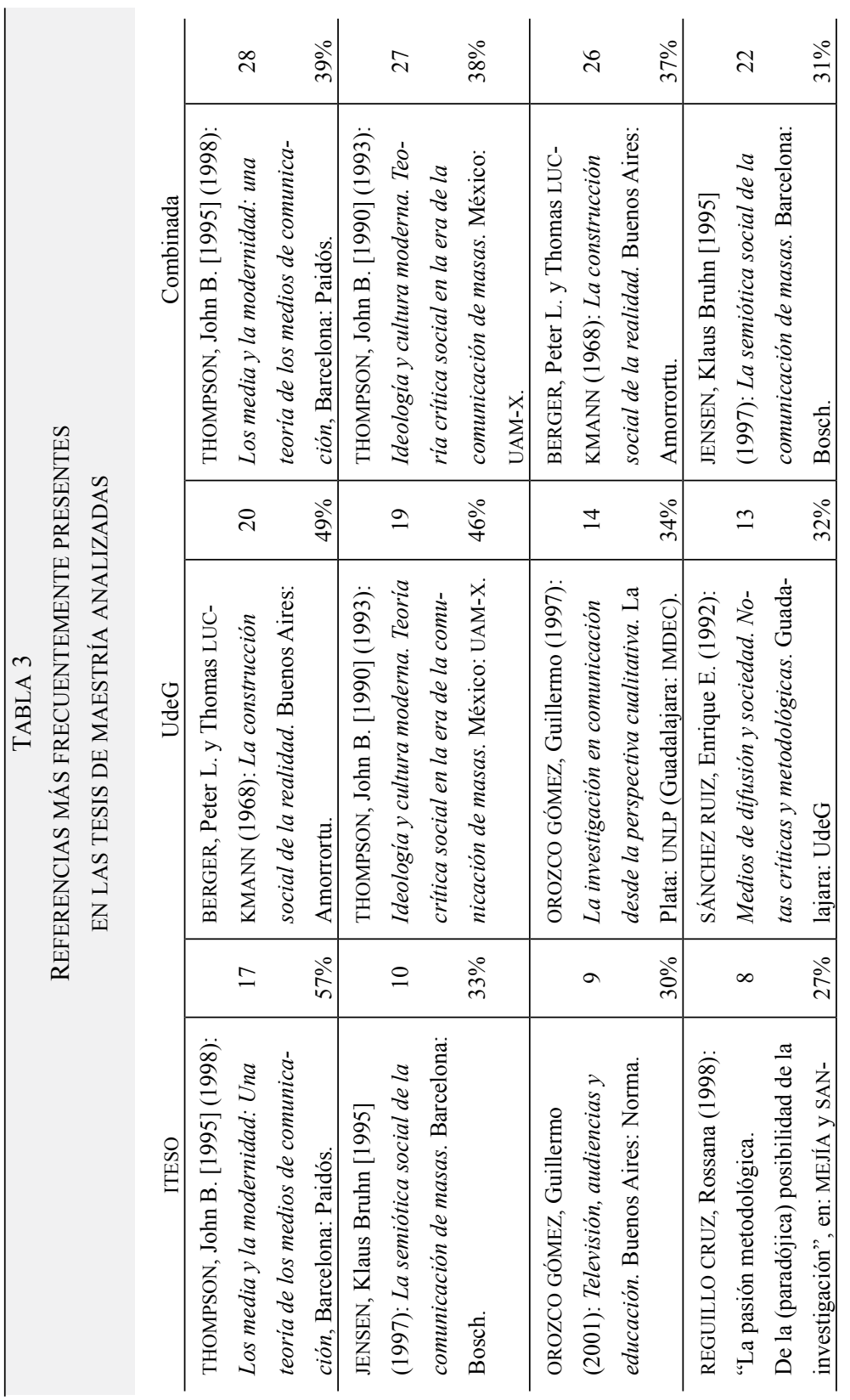




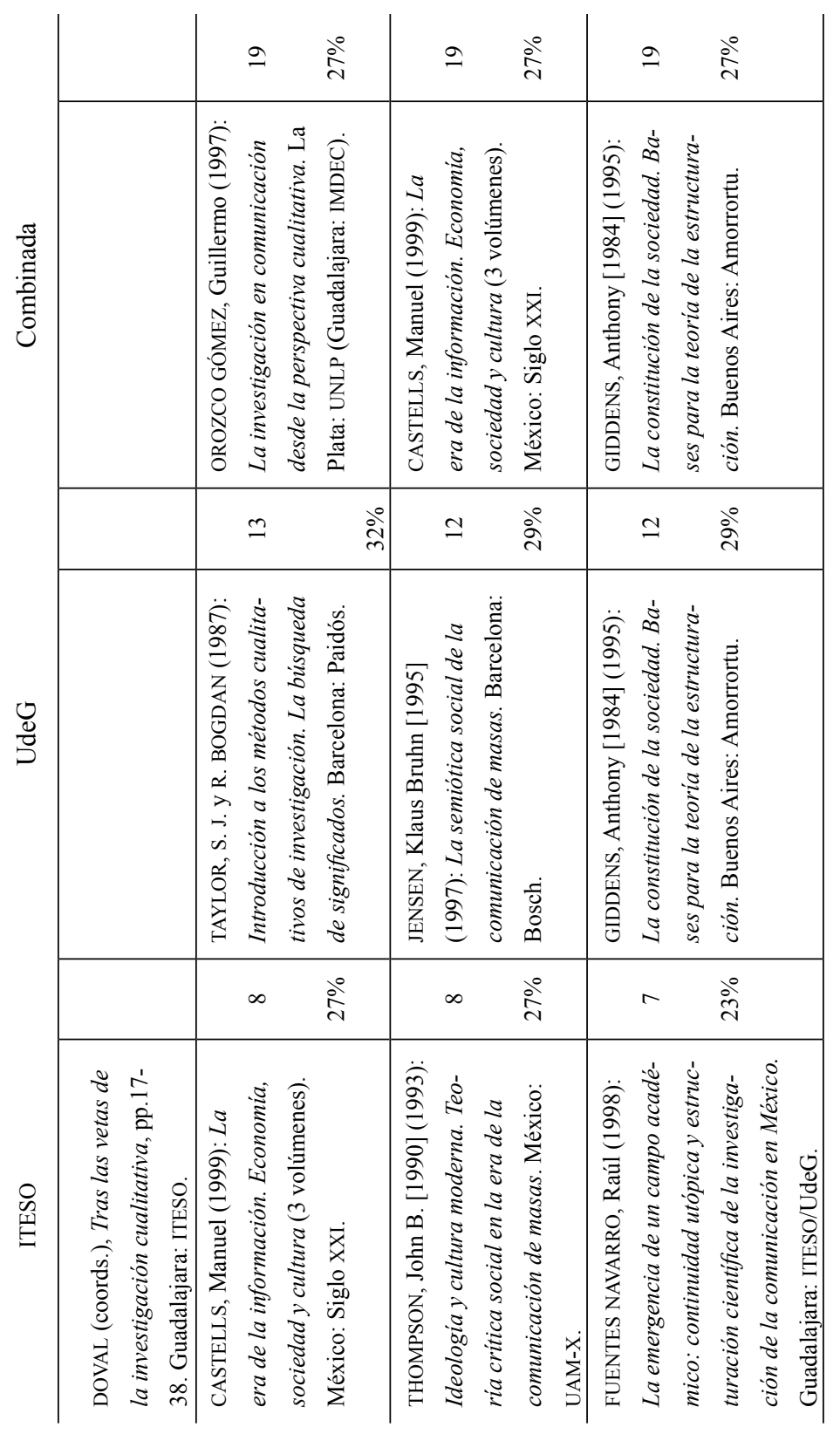




\begin{tabular}{|c|c|c|c|c|c|c|c|c|c|c|c|c|c|c|c|c|c|}
\hline & I & & $\stackrel{\stackrel{\circ}{+}}{d}$ & & & & & & & 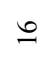 & & 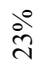 & & & $\because$ & & $\frac{\partial^{\circ}}{\vec{v}}$ \\
\hline 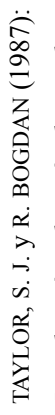 & 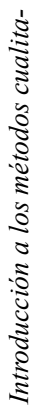 & 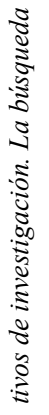 & 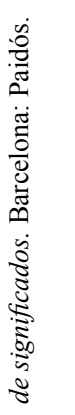 & 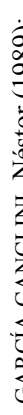 & 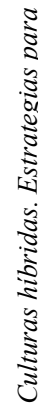 & 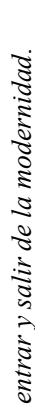 & 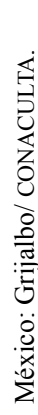 & & 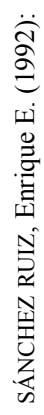 & 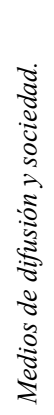 & 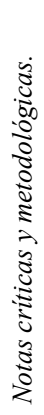 & 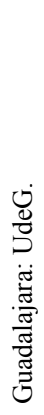 & & 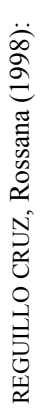 & 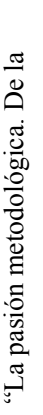 & 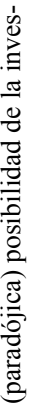 & 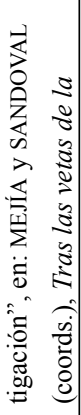 \\
\hline & $\simeq$ & & ڤे & & $\simeq$ & & $\hat{~}$ & & & $=$ & & 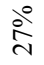 & & & $=$ & & $\stackrel{\stackrel{\circ}{~}}{\sim}$ \\
\hline 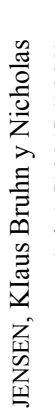 & 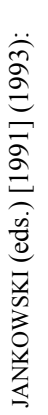 & 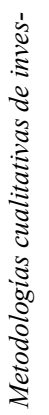 & 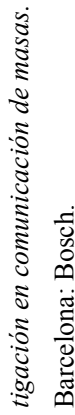 & $\begin{array}{ll}3 \\
0\end{array}$ & 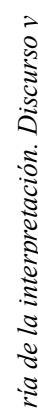 & 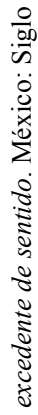 & 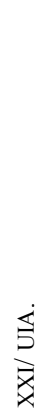 & & 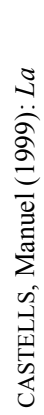 & 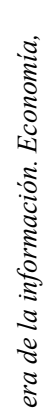 & 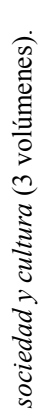 & 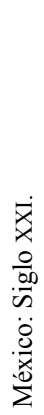 & & 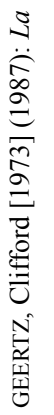 & 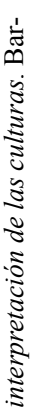 & 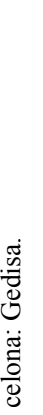 & \\
\hline & $r$ & & ஸें & & $N$ & & & & & $r$ & & ஸें & & & $r$ & & ஸें \\
\hline 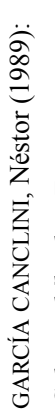 & 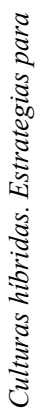 & 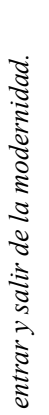 & 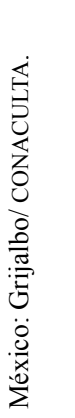 & 2 & 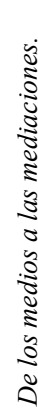 & 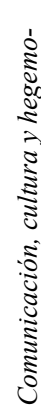 & 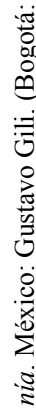 & $\begin{array}{c} \\
\\
\dot{0} \\
\overline{0} \\
0 \\
0 \\
0 \\
0 \\
0 \\
0 \\
0 \\
.0 \\
0 \\
0 \\
0 \\
0\end{array}$ & 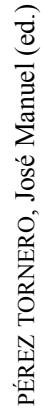 & 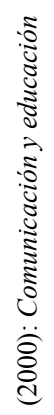 & 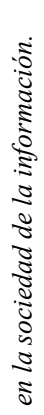 & 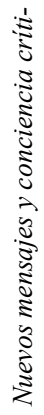 & 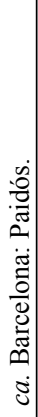 & 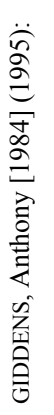 & 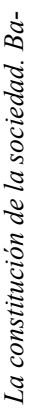 & 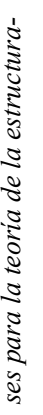 & 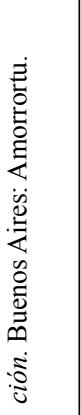 \\
\hline
\end{tabular}




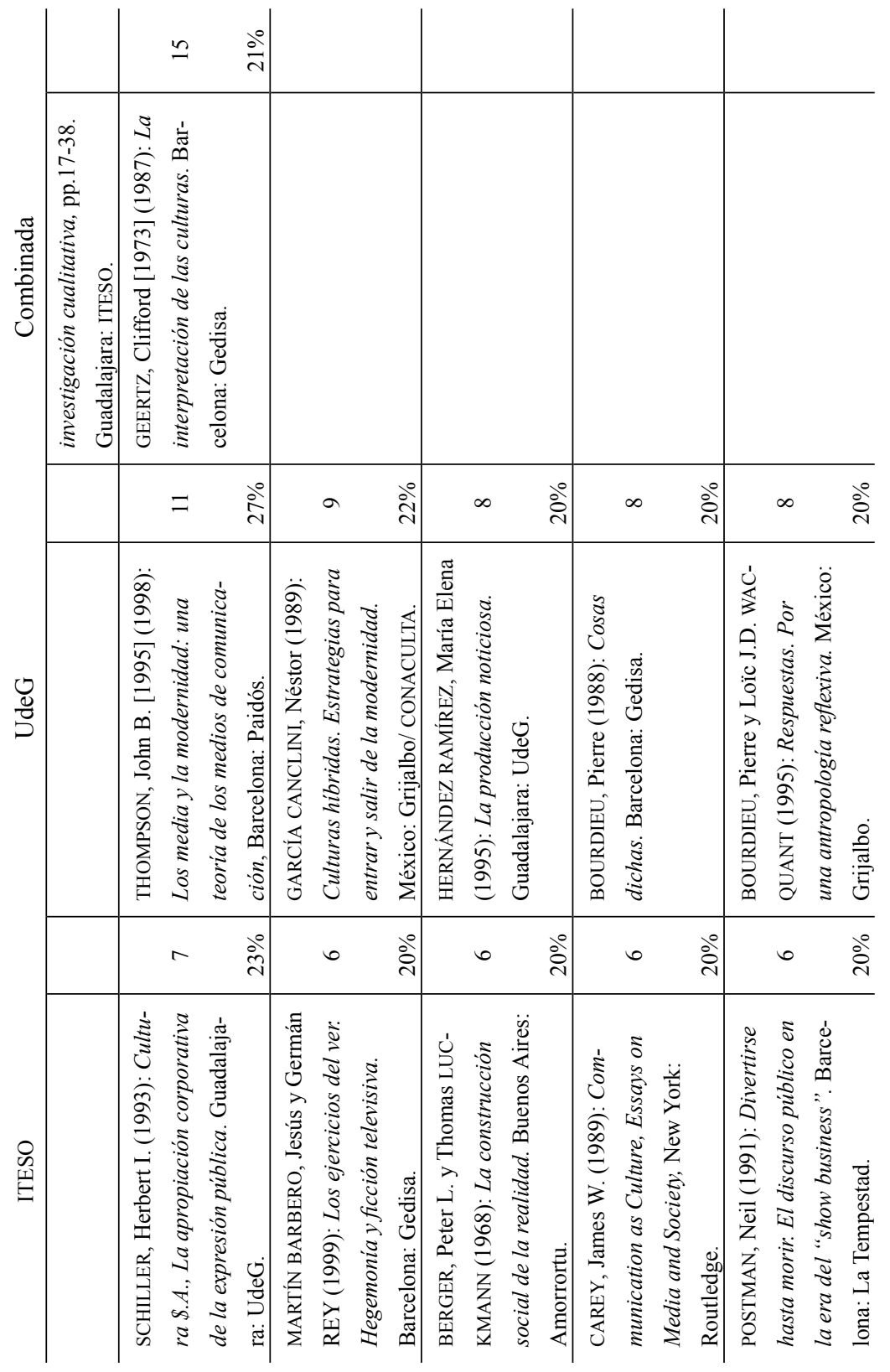


Raúl Fuentes y un capítulo de Rossana Reguillo, único material distinto de un libro que es citado en más de $20 \%$ de las tesis). Cabe destacar que estos cinco investigadores mexicanos son "locales", es decir, que participan directamente como profesores en los programas de maestría del ITESO y la Universidad de Guadalajara, algunos de ellos de manera muy constante en ambas instituciones. Entre las obras de origen iberoamericano, además de la de Castells, están también dos libros de Jesús Martín-Barbero (quien formó parte de la planta académica del ITESO entre 2001 y 2004) y uno editado por José Manuel Pérez Tornero. En síntesis, por su origen, las referencias más frecuentes encontradas en las tesis del ITESO y la Universidad de Guadalajara se distribuyen conforme a lo señalado en la tabla 4 :

\section{TABLA 4}

REFERENCIAS MÁS FRECUENTEMENTE PRESENTES ( $\geq 20 \%$ )

EN LAS TESIS DE MAESTRÍA ANALIZADAS, SEGÚN SU ORIGEN

\begin{tabular}{llll}
\multicolumn{1}{c}{ Origen } & \multicolumn{1}{c}{ ITSESO (16) } & \multicolumn{1}{c}{ UdeG (16) } & \multicolumn{1}{c}{ Combinada (12) } \\
\hline a) Mexicano & $4(25 \%)$ & $4(25 \%)$ & $4(33 \%)$ \\
b) Iberoamericano & $4(25 \%)$ & $1(6 \%)$ & $1(9 \%)$ \\
c) "Extranjero" & $8(50 \%)$ & $11(69 \%)$ & $7(58 \%)$ \\
\hline
\end{tabular}

Conviene analizar y comparar esta composición por origen de las referencias en una muestra mayor, para obtener más claridad en las tendencias. Por ello se recalcularon los porcentajes respectivos tomando en cuenta todas las referencias que aparecieran cuatro o más veces en las mismas tres listas. Los resultados se presentan en la tabla 5:

\section{TABLA 5}

REFERENCIAS MÁS FRECUENTEMENTE PRESENTES $(\geq 4)$

EN LAS TESIS DE MAESTRÍA ANALIZADAS, SEGÚN SU ORIGEN

\begin{tabular}{lccc}
\multicolumn{1}{c}{ Origen } & ITESO (47) & UdeG (73) & Combinada (101) \\
\hline a) Mexicano & $15(32 \%)$ & $23(32 \%)$ & $33(33 \%)$ \\
b) Iberoamericano & $11(23 \%)$ & $9(12 \%)$ & $17(17 \%)$ \\
c) "Extranjero" & $21(45 \%)$ & $41(56 \%)$ & $51(50 \%)$ \\
\hline
\end{tabular}


$\mathrm{Al}$ aumentar el número de referencias consideradas, aunque disminuya su frecuencia, la composición del perfil según el origen cambia en los tres conjuntos ("listas") analizados. En los tres casos el porcentaje de obras mexicanas aumenta, y en dos de los tres también el de obras iberoamericanas. Es decir, conforme se incluyen más referencias menos frecuentemente citadas, disminuye (considerablemente) la proporción de obras de origen "extranjero", que sin embargo siguen dando cuenta de alrededor de la mitad de las referencias. Aunque en esta composición ya no se trata sólo de libros, sino que hay algunos artículos y capítulos y una tesis incluidos, cabe considerar que los libros de autores extranjeros (traducidos al español) constituyen la abrumadora mayoría de la oferta editorial y tienen asegurada una circulación mucho mayor que los de autores mexicanos, cuyo número además, obviamente, es mucho menor. Aun así, es muy significativo el porcentaje de obras mexicanas referidas (alrededor de un tercio de las referencias) en las tesis del ITESO y la Universidad de Guadalajara. Este rasgo, además compartido, tendrá que contrastarse con los perfiles de referencias de las tesis de otras universidades mexicanas, para tener una mejor apreciación del impacto de la investigación mexicana (e iberoamericana) en la reproducción del campo académico manifiesta en las tesis de maestría y del consecuente grado de "independencia" científica del campo. En la tabla 6 se presentan, según su frecuencia combinada en ambas universidades, las 33 obras de origen mexicano más citadas en las tesis analizadas:

\section{TABLA 6}

REFERENCIAS DE ORIGEN MEXICANO EN

LAS TESIS DE MAESTRÍA ANALIZADAS

\begin{tabular}{lccc} 
& ITESO & UdeG & Comb. \\
\hline OROZCO GÓMEZ, Guillermo (1997): La inves- & 5 & 14 & 19 \\
tigación en comunicación desde la perspecti- & & & \\
va cualitativa. La Plata: UNLP (Guadalajara: & & & \\
IMDEC). & & & \\
GARCÍA CANCLINI, Néstor (1989): Culturas & 7 & 9 & 16 \\
híbridas. Estrategias para entrar y salir de la & & & \\
modernidad. México: Grijalbo/ CONACULTA. & & &
\end{tabular}




\begin{tabular}{|c|c|c|c|}
\hline & ITESO & UdeG & Comb. \\
\hline $\begin{array}{l}\text { SÁNCHEZ RUIZ, Enrique E. (1992): Medios de } \\
\text { difusión y sociedad. Notas criticas y metodo- } \\
\text { lógicas. Guadalajara: UdeG. }\end{array}$ & 3 & 13 & 16 \\
\hline $\begin{array}{l}\text { REGUILLO CRUZ, Rossana (1998): “La pasión } \\
\text { metodológica. De la (paradójica) posibilidad } \\
\text { de la investigación”, en: MEJÍA y SANDOVAL } \\
\text { (coords.), Tras las vetas de la investigación } \\
\text { cualitativa, pp.17-38. Guadalajara: ITESO. }\end{array}$ & 8 & 7 & 15 \\
\hline $\begin{array}{l}\text { FUENTES NAVARRO, Raúl (1996): La investi- } \\
\text { gación de la comunicación en México. Siste- } \\
\text { matización documental 1986-1994. Guadala- } \\
\text { jara: ITESO/UdeG. }\end{array}$ & 5 & 7 & 12 \\
\hline $\begin{array}{l}\text { FUENTES NAVARRO, Raúl (1988): La inves- } \\
\text { tigación de comunicación en México. Siste- } \\
\text { matizacion documental 1956-1986. México: } \\
\text { Edicom. }\end{array}$ & 5 & 6 & 11 \\
\hline $\begin{array}{l}\text { OROZCO GÓMEZ, Guillermo (2001): Televi- } \\
\text { sión, audiencias y educación. Buenos Aires: } \\
\text { Norma. }\end{array}$ & 9 & 2 & 11 \\
\hline $\begin{array}{l}\text { OROZCO GÓMEZ, Guillermo (1996): Tele- } \\
\text { visión y Audiencias, un enfoque cualitativo. } \\
\text { Madrid: Ediciones de la Torre/ UIA. }\end{array}$ & 5 & 4 & 9 \\
\hline $\begin{array}{l}\text { FUENTES NAVARRO, Raúl (1998): La emer- } \\
\text { gencia de un campo académico: continuidad } \\
\text { utópica y estructuración cientifica de la in- } \\
\text { vestigación de la comunicación en México. } \\
\text { Guadalajara: ITESO/UdeG. }\end{array}$ & 7 & 1 & 8 \\
\hline $\begin{array}{l}\text { GARCÍA CANCLINI, Néstor (1995): Consumi- } \\
\text { dores y ciudadanos. Conflictos multicultura- } \\
\text { les de la globalización. México: Grijalbo. }\end{array}$ & 4 & 4 & 8 \\
\hline $\begin{array}{l}\text { OROZCO GÓMEZ, Guillermo (1991): Recep- } \\
\text { ción televisiva. Tres aproximaciones y una ra- } \\
\text { zón para su estudio. México: UIA (Cuadernos } \\
\text { de Comunicación y Prácticas Sociales núm 2). }\end{array}$ & 5 & 3 & 8 \\
\hline
\end{tabular}




\begin{tabular}{|c|c|c|c|}
\hline & ITESO & UdeG & Comb. \\
\hline $\begin{array}{l}\text { REGUILLO CRUZ, Rossana (1995): En la calle } \\
\text { otra vez. Las bandas: identidad urbana y usos } \\
\text { de la comunicación. Guadalajara: ITESO. }\end{array}$ & 2 & 6 & 8 \\
\hline $\begin{array}{l}\text { FUENTES NAVARRO, Raúl (2000): Educación } \\
\text { y telemática. Buenos Aires: Norma. }\end{array}$ & 5 & 2 & 7 \\
\hline $\begin{array}{l}\text { FUENTES NAVARRO, Raúl (1991): La comuni- } \\
\text { dad desapercibida: investigación e investiga- } \\
\text { dores de la comunicación en México. Guada- } \\
\text { lajara: ITESO/ CONEICC. }\end{array}$ & 2 & 4 & 6 \\
\hline $\begin{array}{l}\text { FERNÁNDEZ COLLADO, Carlos; Pilar BAPTIS- } \\
\text { TA y Débora ELKES (1986): La televisión y el } \\
\text { niño. México: Oasis. }\end{array}$ & 1 & 4 & 5 \\
\hline $\begin{array}{l}\text { GALINDO CÁCERES, Jesús (comp.) (1998): } \\
\text { Técnicas de investigación en sociedad, cultu- } \\
\text { ra y comunicación. México: Addison Wesley } \\
\text { Longman. }\end{array}$ & 3 & 2 & 5 \\
\hline $\begin{array}{l}\text { GARCÍA CANCLINI, Néstor (coord.) (1993): } \\
\text { El consumo cultural en México. México: CO- } \\
\text { NACULTA. }\end{array}$ & 3 & 2 & 5 \\
\hline $\begin{array}{l}\text { OROZCO GÓMEZ, Guillermo (1997): La in- } \\
\text { vestigación de la comunicación dentro y fuera } \\
\text { de América Latina. Tendencias, perspectivas } \\
\text { y desafios del estudio de los medios. La Plata: } \\
\text { UNLP. }\end{array}$ & 3 & 2 & 5 \\
\hline $\begin{array}{l}\text { REGUILLO CRUZ, Rossana (1996): La cons- } \\
\text { trucción simbólica de la ciudad. Sociedad, } \\
\text { desastre, comunicación. Guadalajara: ITESO/ } \\
\text { UIA. }\end{array}$ & 3 & 2 & 5 \\
\hline $\begin{array}{l}\text { RUIZ DUEÑAS, Jorge (2000): Cultura, ¿para } \\
\text { qué?, un examen comparado. México: Océa- } \\
\text { no. }\end{array}$ & 4 & 1 & 5 \\
\hline $\begin{array}{l}\text { SÁNCHEZ RUIZ, Enrique E. (1992): Tenden- } \\
\text { cias en la investigación sobre televisión en } \\
\text { México 1950- 1990. Guadalajara: UdeG. }\end{array}$ & 2 & 3 & 5 \\
\hline
\end{tabular}


ITESO UdeG Comb.

SÁNCHEZ RUIZ, Enrique E. (2000): "Industrias

2

3

5

culturales y globalización. Un enfoque histórico estructural", en OROZCO (coord.) Lo viejo y lo nuevo. Investigar la comunicación en el siglo XXI. Madrid: Ediciones de la Torre.

ESTEINOU MADRID, Javier (1983): Los me-

dios de comunicación y la construcción de la hegemonía. México: CEESTEM / Nueva Imagen (Trillas).

FUENTES NAVARRO, Raúl (2003): La inves-

tigación académica sobre comunicación en México. Sistematización documental 19952001. Guadalajara: ITESO.

FUENTES NAVARRO, Raúl (1997): “Consoli-

dación y fragmentación de la investigación de la comunicación en México, 1987-1997”, en Comunicación y Sociedad núm. 30, Guadalajara: UdeG.

GALINDO CÁCERES, Jesús (1987): “Encuentro de subjetividades, objetividad descubierta. La entrevista como centro de trabajo etnográfico", en Estudios sobre las culturas contemporáneas 1 (3). Colima: UdeC.

GALINDO CÁCERES, Jesús (1997): Sabor a ti. Metodología cualitativa en investigación social. Xalapa: Universidad Veracruzana.

GIMÉNEZ MONTIEL, Gilberto (1982): La pro-

blemática de la cultura en las ciencias sociales. México: IIS UNAM.

GIMÉNEZ MONTIEL, Gilberto (1999): "La im-

portancia estratégica de los estudios culturales en el campo de las ciencias sociales", en REGUILLO y FUENTES (coords.), Pensar las ciencias sociales hoy. Reflexiones desde la cultura. Guadalajara: ITESO. 


\begin{tabular}{|c|c|c|c|}
\hline & ITESO & UdeG & Comb. \\
\hline $\begin{array}{l}\text { GONZÁLEZ S., Jorge A. y Jesús GALINDO } \\
\text { C. (coords.) (1994): Metodología y cultura. } \\
\text { México: CONACULTA. }\end{array}$ & 1 & 3 & 4 \\
\hline $\begin{array}{l}\text { LOZANO RENDÓN, José Carlos (1994): "Hacia } \\
\text { la reconsideración del análisis del contenido } \\
\text { en la investigación de los mensajes comuni- } \\
\text { cacionales", en CERVANTES y SÁNCHEZ (Co- } \\
\text { ords.), Investigar la comunicación. Propuestas } \\
\text { iberoamericanas. Guadalajara: UdeG/ ALAIC. }\end{array}$ & 1 & 3 & 4 \\
\hline $\begin{array}{l}\text { REGUILLO CRUZ, Rossana (1997): "Más allá } \\
\text { de los medios. Diez años después", en Comu- } \\
\text { nicación y Sociedad núm. 30. Guadalajara: } \\
\text { UdeG. }\end{array}$ & 2 & 2 & 4 \\
\hline $\begin{array}{l}\text { Instituto Mexicano de la Juventud (2001): En- } \\
\text { cuesta Nacional de la Juventud 2000, jóvenes } \\
\text { mexicanos del siglo XXI, México: SEP- IMJ. }\end{array}$ & 3 & 1 & 4 \\
\hline
\end{tabular}

Es evidente que para los autores de las tesis de maestría del ITESO y la Universidad de Guadalajara, las publicaciones de algunos de sus profesores son materiales de referencia importantes. 19 de las 33 referencias de origen mexicano incluidas en la tabla 6 corresponden a cuatro profesores del ITESO y/o la Universidad de Guadalajara, de quienes se citan en las tesis distintas publicaciones (siete de Raúl Fuentes, cinco de Guillermo Orozco, cuatro de Rossana Reguillo y tres de Enrique Sánchez Ruiz). Este dato apunta a que, además de ser académicos "locales", estos cuatro investigadores están entre los que cuentan con mayor número de publicaciones en los últimos años en el país (Fuentes, 2003: 21).

De acuerdo con los datos hasta aquí presentados, hay fuertes indicios de una amplia zona de confluencia académica en los perfiles de referencias de las tesis de maestría en comunicación presentadas en los últimos años en el ITESO y la Universidad de Guadalajara. A pesar de tratarse de dos instituciones de educación superior muy diferentes (una institución pública de gran tamaño y una universidad privada de escala mediana), y con trayectorias diversas y hasta opuestas en su participa- 
ción en el campo académico de la comunicación ${ }^{8}$, ha habido durante dos décadas un muy intenso y variado intercambio académico entre ambas, especialmente en el nivel de desarrollo de sus respectivas plantas académicas 9 . No obstante que los programas de maestría difieren sustancialmente en su estructura curricular ${ }^{10} \mathrm{y}$ en sus costos de matrícula, mantienen los parámetros y condiciones comunes del Padrón

8 El ITESO fue una de las primeras instituciones mexicanas donde se estableció una licenciatura en ciencias de la comunicación (1967), y donde en 1985 se abrió un programa de maestría en comunicación y en 2002 de doctorado (en estudios científico-sociales, con un área de "comunicación, cultura y sociedad"); mientras que la Universidad de Guadalajara creó primero, en 1986, un centro de investigación y la revista Comunicación y Sociedad, para luego participar con especialidades en comunicación en programas de maestría (1994) y doctorado en ciencias sociales (1991) y en educación (1998), hasta finalmente abrir una licenciatura en comunicación pública en 2007 .

9 Una alta proporción de los académicos adscritos al Departamento de Estudios de la Comunicación Social de la Universidad de Guadalajara realizó sus estudios de licenciatura en ciencias de la comunicación en el ITESO, y una alta proporción de la planta académica del Departamento de Estudios Socioculturales del ITESO realizó estudios de posgrado en la Universidad de Guadalajara.

10 La maestría en comunicación de la Universidad de Guadalajara admite nuevos estudiantes "generacionalmente", con ingreso cada dos años, y su plan de estudios comprende cuatro áreas: de Fundamentación teórico-metodológica, de Métodos, técnicas y recursos de investigación, de Articulaciones multidisciplinarias, y de Producción de investigación, cada una formada por cuatro seminarios semestrales de secuencia fija. Por su parte, la maestría en comunicación de la ciencia y la cultura del ITESO mantiene el ingreso abierto permanentemente y un curriculum extremadamente flexible, de manera que cada estudiante opta por el orden en que cubrirá las 16 asignaturas semestrales que comprenden las áreas comunes y obligatorias de fundamentación y de proyectos de tesis, así como las áreas optativas de concentración (en comunicación pública de la ciencia o de estudios socioculturales) y complementaria. 
Nacional de Posgrado, donde ambos programas han sido calificados como de "alto nivel", por lo cual la mayoría de sus estudiantes tiende a serlo "de tiempo completo" y poder así hacerse acreedores a una beca del CONACyT, con la condición de graduarse en un plazo menor a tres años a partir de su ingreso.

Tanto en el ITESO como en la Universidad de Guadalajara hay una alta variedad de construcciones temático-referenciales en las tesis de maestría, por lo que un primer acercamiento de clasificación permite detectar muchas más coincidencias entre las dos instituciones que especificidades excluyentes en este nivel. Sólo dos de las diez categorías provisionalmente diseñadas para esta clasificación, indican una perspectiva de estudio sobre objetos que no se encuentran en la otra institución. En la tabla 7 se exponen los resultados de este ejercicio:

\section{TABLA 7}

CARACTERIZACIÓN TEMÁTICO-REFERENCIAL DE LAS TESIS ANALIZADAS

\begin{tabular}{lccc} 
& ITESO & UdeG & Total \\
\hline Comunicación - cultura & $5(17 \%)$ & $8(20 \%)$ & $13(19 \%)$ \\
Periodismo & 0 & 13 & $13(19 \%)$ \\
& & $(32 \%)$ & \\
Comunicación - educación & $7(23 \%)$ & $5(12 \%)$ & $12(17 \%)$ \\
Televisión & $5(17 \%)$ & $6(15 \%)$ & $11(15 \%)$ \\
Comunicación - análisis institucional & $3(10 \%)$ & $3(7 \%)$ & $6(8 \%)$ \\
Campo académico de la comunicación & $4(13 \%)$ & $2(5 \%)$ & $6(8 \%)$ \\
Medios digitales - computación & $2(7 \%)$ & $1(2 \%)$ & $3(4 \%)$ \\
Comunicación/cultura urbana & $1(3 \%)$ & $2(5 \%)$ & $3(4 \%)$ \\
Radio & $1(3 \%)$ & $1(2 \%)$ & $2(3 \%)$ \\
Comunicación de la ciencia & $2(7 \%)$ & 0 & $2(3 \%)$ \\
\hline
\end{tabular}

Es claro que en la Universidad de Guadalajara se cultivan investigaciones sobre la producción y circulación periodísticas, y que en el ITESO se hace lo propio sobre la comunicación de la ciencia, lo cual no sucede en la otra institución. Pero las otras ocho categorías indican que los recortes temático-referenciales así indicados están representados en 
ambas universidades, aparentemente sin notables diferencias. Como en otros aspectos, la comparación con las tesis producidas en las maestrías de otras instituciones habrá de permitir refinar las categorías y contar con mejores elementos para interpretar las tendencias de confluencia y especialización (de campo) y de diferenciación (por institución). Lo mismo vale para las dimensiones teórico-metodológicas y epistemológicas involucradas.

Es necesario recalcar, para concluir, el carácter de "primer acercamiento" descriptivo al material de estudio presente en las bibliografías de las tesis de maestría, que permite descubrir algunas tendencias, constantes y variantes sobre las cuales no hay todavía el suficiente trabajo analítico y contextual como para intentar explicaciones o hipótesis demasiado precisas, pero que conducen a encuadrar, en un marco de rigor científico y pertinencia social, preguntas de fondo sobre la constitución del campo académico de la comunicación y las condiciones de la profesionalización avanzada en él.

\section{Bibliografía}

BOURDIEU, Pierre (1988) Homo Academicus. California: Stanford University Press.

- (2000) Los usos sociales de la ciencia. Buenos Aires: Nueva Visión.

BUSTAMANTE FARÍAS, Óscar (2004) Sistematización analítica de la oferta de posgrados de comunicación en América Latina. Tesis de maestría en comunicación con especialidad en difusión de la ciencia y la cultura. Guadalajara: ITESO.

- (2006) "Posgrados en comunicación en América Latina: descripción analítica de la oferta y una propuesta de sentido", en Fuentes (coord.), Instituciones y redes académicas para el estudio de la comunicación en América Latina. Guadalajara: ITESO.

CALlON, Michel, Jean-Pierre Courtial y Hervé Penan (1995) Cienciometría. El estudio cuantitativo de la actividad cientifica: de la bibliometría a la vigilancia tecnológica. Gijón: Trea.

CAMPANARIO, Juan Miguel (2003) "Citation Analysis", International Encyclopaedia of Information and Library Science, 2nd Edition, John Feather and Paul Sturges (eds). London: Routledge. 
CAPPARELli, Sérgio e Ida Regina C. Stumpf (2001) "El campo académico de la comunicación, revisitado", en Vassallo De Lopes y Fuentes (comps.) Comunicación, campo y objeto de estudio. Perspectivas reflexivas latinoamericanas. Guadalajara: ITESO/ U. A. de Aguascalientes/ U. de Colima/ U. de Guadalajara.

De la Torre Escoto, Gabriela (2003) La reproducción del campo académico de la comunicación en México. Un análisis de las tesis de maestría en comunicación (1996-2000). Tesis de maestría en comunicación con especialidad en difusión de la ciencia y la cultura. Guadalajara: ITESO.

- (2004) "La reproducción del campo académico de la comunicación en México: un análisis de las tesis de maestría (1996-2000)", en Fuentes (coord.), Producción, circulación y reproducción académicas en el campo de la comunicación en México. Guadalajara: ITESO.

- y Raúl Fuentes Navarro (2002) "Producción de conocimiento y formación de investigadores. Un análisis de las tesis de maestría en comunicación en México (1996-2000)", en Anuario de Investigación de la Comunicación IX. México: Consejo Nacional para la Enseñanza y la Investigación de las Ciencias de la Comunicación.

FUENTES NAVARRO, Raúl (1998) La emergencia de un campo académico: continuidad utópica y estructuración científica de la investigación de la comunicación en México. Guadalajara: ITESO/ Universidad de Guadalajara.

- (2003) La investigación académica sobre comunicación en México, sistematización documental 1995-2001. Guadalajara: ITESO.

GORBEA PORTAL, Salvador (2005): El modelo matemático de Lotka: su aplicación a la producción científica latinoamericana en ciencias bibliotecológica y de la información. México: UNAM, Centro Universitario de Investigaciones Bibliotecológicas.

HICKS, Diana (2004) "The Four Literatures of Social Science", in Handbook of Quantitative Science and Technology Research, Henk Moed (ed.), Kluwer Academic. 


\begin{tabular}{|c|c|c|c|}
\hline \multicolumn{4}{|c|}{$\begin{array}{c}\text { ANEXO } \\
\text { TESIS ANALIZADAS DE MAESTRÍA EN COMUNICACIÓN } \\
\text { ITESO }\end{array}$} \\
\hline Autor & Año & Título & Asesor \\
\hline $\begin{array}{l}\text { BELTRÁN SANTIAGO, } \\
\text { Gabriel (primera ver- } \\
\text { sión de la maestría) }\end{array}$ & 1997 & $\begin{array}{l}\text { Plan DENI y la recepción interac- } \\
\text { tiva del niño ante el televisor. }\end{array}$ & $\begin{array}{l}\text { Raúl Fuentes } \\
\text { Navarro }\end{array}$ \\
\hline $\begin{array}{l}\text { CHAN NÚÑEZ, María } \\
\text { Elena (primera versión } \\
\text { de la maestría) }\end{array}$ & 1999 & $\begin{array}{l}\text { Rutas hacia el significado como } \\
\text { tarea colectiva. Aplicaciones de } \\
\text { la semiótica en la articulación } \\
\text { multidisciplinaria de lenguajes } \\
\text { y códigos para la producción de } \\
\text { materiales educativos. }\end{array}$ & $\begin{array}{l}\text { Raúl Fuentes } \\
\text { Navarro }\end{array}$ \\
\hline $\begin{array}{l}\text { CORRALES DÍAZ, Car- } \\
\text { los (primera versión de } \\
\text { la maestría) }\end{array}$ & 1999 & $\begin{array}{l}\text { La profesión del comunicador. Un } \\
\text { acercamiento praxeológico. }\end{array}$ & $\begin{array}{l}\text { Raúl Fuentes } \\
\text { Navarro }\end{array}$ \\
\hline $\begin{array}{l}\text { HERNÁNDEZ BARBA, } \\
\text { Alfonso }\end{array}$ & 2002 & $\begin{array}{l}\text { CONACULTA en Internet: políticas } \\
\text { culturales y reproducción institu- } \\
\text { cional. }\end{array}$ & $\begin{array}{l}\text { Raúl Fuentes } \\
\text { Navarro }\end{array}$ \\
\hline $\begin{array}{l}\text { HERRERA LIMA, Su- } \\
\text { sana }\end{array}$ & 2002 & $\begin{array}{l}\text { Los sistemas de representación } \\
\text { comunicacionales: una red de in- } \\
\text { terfaces tendida en el espacio de } \\
\text { la ecología cognitiva. }\end{array}$ & $\begin{array}{l}\text { Raúl Fuentes } \\
\text { Navarro }\end{array}$ \\
\hline $\begin{array}{l}\text { MARROQUÍN PARDUC- } \\
\text { CI, Amparo }\end{array}$ & 2003 & $\begin{array}{l}\text { Maestros y lenguajes: aproxima- } \\
\text { ción a una ruptura. Medios para } \\
\text { un encuentro. }\end{array}$ & $\begin{array}{l}\text { Guillermo } \\
\text { Orozco } \\
\text { Gómez }\end{array}$ \\
\hline $\begin{array}{l}\text { ONTIVEROS FLORES, } \\
\text { Adriana Patricia }\end{array}$ & 2003 & $\begin{array}{l}\text { El maestro y la televisión frente } \\
\text { a frente. Una propuesta de educa- } \\
\text { ción para los medios. }\end{array}$ & $\begin{array}{l}\text { Guillermo } \\
\text { Orozco } \\
\text { Gómez }\end{array}$ \\
\hline $\begin{array}{l}\text { VICTORIANO REYES, } \\
\text { José A. }\end{array}$ & 2003 & $\begin{array}{l}\text { Radios populares: del paradigma } \\
\text { ilustrado en la comunicación par- } \\
\text { ticipativa a la construcción de la } \\
\text { participación ciudadana. }\end{array}$ & $\begin{array}{l}\text { Guillermo } \\
\text { Orozco } \\
\text { Gómez }\end{array}$ \\
\hline $\begin{array}{l}\text { DE LA TORRE ESCOTO, } \\
\text { Gabriela }\end{array}$ & 2003 & $\begin{array}{l}\text { La reproducción del campo aca- } \\
\text { démico de la comunicación en }\end{array}$ & $\begin{array}{l}\text { Raúl Fuentes } \\
\text { Navarro }\end{array}$ \\
\hline
\end{tabular}




\begin{tabular}{|c|c|c|c|}
\hline Autor & Año & Título & Asesor \\
\hline & & $\begin{array}{l}\text { México. Un análisis de las tesis de } \\
\text { maestría en comunicación (1996- } \\
\text { 2000). }\end{array}$ & \\
\hline $\begin{array}{l}\text { PÁEZ KANO, José } \\
\text { Rubén }\end{array}$ & 2003 & $\begin{array}{l}\text { La esfera. La tierra plana medieval } \\
\text { como invención del siglo XIX. }\end{array}$ & $\begin{array}{l}\text { Raúl Fuentes } \\
\text { Navarro }\end{array}$ \\
\hline $\begin{array}{l}\text { QUINTERO TAPIA, Ós- } \\
\text { car Alfredo }\end{array}$ & 2003 & $\begin{array}{l}\text { Centro de Acceso de Oblatos: } \\
\text { retórica y realidad de los usos y las } \\
\text { posibilidades de uso de las nuevas } \\
\text { tecnologías de información y co- } \\
\text { municación. }\end{array}$ & $\begin{array}{l}\text { Raúl Fuentes } \\
\text { Navarro }\end{array}$ \\
\hline $\begin{array}{l}\text { RAMÍREZ y RAMÍREZ, } \\
\text { Karla Margarita }\end{array}$ & 2003 & $\begin{array}{l}\text { Destellos de la comunicación. La } \\
\text { diseminación de conocimiento a } \\
\text { través de las publicaciones aca- } \\
\text { démicas. } \\
\text { (PREMIO NACIONAL CONEICC } \\
2003 \text { ) }\end{array}$ & $\begin{array}{l}\text { Raúl Fuentes } \\
\text { Navarro }\end{array}$ \\
\hline $\begin{array}{l}\text { LÓPEZ MIJARES, An- } \\
\text { tonio }\end{array}$ & 2004 & $\begin{array}{l}\text { La vida política de México y la } \\
\text { revista Plural de Octavio Paz } \\
(1971-1976) .\end{array}$ & $\begin{array}{l}\text { Carlos Enrique } \\
\text { Orozco } \\
\text { Martínez }\end{array}$ \\
\hline $\begin{array}{l}\text { MORENO GUÍZAR, } \\
\text { Elvia }\end{array}$ & 2004 & $\begin{array}{l}\text { Escorzo de la política cultural en } \\
\text { México. Una mirada a través de } \\
\text { los reconocimientos nacionales de } \\
\text { ciencia y cultura (1940-2000). }\end{array}$ & $\begin{array}{l}\text { Carlos Enrique } \\
\text { Orozco } \\
\text { Martínez }\end{array}$ \\
\hline $\begin{array}{l}\text { OCAMPO DE LA TO- } \\
\text { RRE, Óscar }\end{array}$ & 2004 & $\begin{array}{l}\text { Lectura y cultura: lo que leer } \\
\text { significa en los municipios de Gua- } \\
\text { dalajara, Zapopan y Tlajomulco de } \\
\text { Zúñiga en el estado de Jalisco. }\end{array}$ & $\begin{array}{l}\text { Diana } \\
\text { Sagástegui } \\
\text { Rodríguez }\end{array}$ \\
\hline $\begin{array}{l}\text { BUSTAMANTE FARÍAS, } \\
\text { Óscar }\end{array}$ & 2004 & $\begin{array}{l}\text { Sistematización analítica de la } \\
\text { oferta de posgrados de comunica- } \\
\text { ción en América Latina. }\end{array}$ & $\begin{array}{l}\text { Guillermo } \\
\text { Orozco } \\
\text { Gómez }\end{array}$ \\
\hline $\begin{array}{l}\text { QUESADA GARCÍA, } \\
\text { Narda Isabel }\end{array}$ & 2004 & $\begin{array}{l}\text { Las relaciones entre el presidente } \\
\text { Fox y la televisión. Un nuevo } \\
\text { pacto político. }\end{array}$ & $\begin{array}{l}\text { Guillermo } \\
\text { Orozco } \\
\text { Gómez }\end{array}$ \\
\hline $\begin{array}{l}\text { REYES PERLES, Alma } \\
\text { Gloria }\end{array}$ & 2004 & $\begin{array}{l}\text { Participación ciudadana en la tele- } \\
\text { visión mexicana. }\end{array}$ & $\begin{array}{l}\text { Guillermo } \\
\text { Orozco } \\
\text { Gómez }\end{array}$ \\
\hline
\end{tabular}




\begin{tabular}{|c|c|c|c|}
\hline Autor & Año & Título & Asesor \\
\hline $\begin{array}{l}\text { AMÉZQUITA CASTA- } \\
\text { ÑEDA, Irma }\end{array}$ & 2004 & $\begin{array}{l}\text { Nuevos museos: espacios públicos } \\
\text { de aprendizaje. }\end{array}$ & $\begin{array}{l}\text { Raúl Fuentes } \\
\text { Navarro }\end{array}$ \\
\hline $\begin{array}{l}\text { GONZÁLEZ HERNÁN- } \\
\text { DEZ, David }\end{array}$ & 2004 & $\begin{array}{l}\text { El sueño americano en México. } \\
\text { Televisión estadounidense y au- } \\
\text { diencias juveniles en Tijuana. } \\
\text { (PREMIO NACIONAL CONEICC } \\
2004 \text { ). }\end{array}$ & $\begin{array}{l}\text { Raúl Fuentes } \\
\text { Navarro }\end{array}$ \\
\hline $\begin{array}{l}\text { OBREGÓN RODRÍ- } \\
\text { GUEZ, Carmen }\end{array}$ & 2004 & $\begin{array}{l}\text { El discurso disciplinario de la } \\
\text { enseñanza superior: un ejercicio } \\
\text { de acercamiento a las disciplinas } \\
\text { como culturas. }\end{array}$ & $\begin{array}{l}\text { Raúl Fuentes } \\
\text { Navarro }\end{array}$ \\
\hline $\begin{array}{l}\text { GODOY FAJARDO, } \\
\text { Ángela María (primera } \\
\text { versión de la maestría) }\end{array}$ & 2004 & $\begin{array}{l}\text { El caleidoscopio de Darwin y } \\
\text { Zapata. Un análisis de las redes } \\
\text { del campo académico a través de } \\
\text { la revista Diá-logos de la Comu- } \\
\text { nicación. }\end{array}$ & $\begin{array}{l}\text { Raúl Fuentes } \\
\text { Navarro }\end{array}$ \\
\hline $\begin{array}{l}\text { NAVARRO WESTPHA- } \\
\text { LEN, Ana Mariza }\end{array}$ & 2005 & $\begin{array}{l}\text { La construcción del imaginario } \\
\text { social de cultura a partir de las } \\
\text { prácticas del Instituto Cultural de } \\
\text { León y el periódico } A M \text {. }\end{array}$ & $\begin{array}{l}\text { Carlos Enrique } \\
\text { Orozco } \\
\text { Martínez }\end{array}$ \\
\hline $\begin{array}{l}\text { LARA GONZÁLEZ, } \\
\text { Carlos A. }\end{array}$ & 2005 & $\begin{array}{l}\text { El patrimonio cultural en México, } \\
\text { un recurso estratégico para el } \\
\text { desarrollo. }\end{array}$ & $\begin{array}{l}\text { Diana } \\
\text { Sagástegui } \\
\text { Rodríguez }\end{array}$ \\
\hline $\begin{array}{l}\text { SOLANO AGUILAR, } \\
\text { Gabriela }\end{array}$ & 2005 & $\begin{array}{l}\text { La silueta de la infancia a través } \\
\text { del Museo Infantil Interactivo. }\end{array}$ & $\begin{array}{l}\text { Diana } \\
\text { Sagástegui } \\
\text { Rodríguez }\end{array}$ \\
\hline $\begin{array}{l}\text { CORONADO ROJANO, } \\
\text { Eliete Alejandra }\end{array}$ & 2005 & $\begin{array}{l}\text { Audiencias jóvenes y prácticas } \\
\text { sexuales. }\end{array}$ & $\begin{array}{l}\text { Guillermo } \\
\text { Orozco } \\
\text { Gómez }\end{array}$ \\
\hline $\begin{array}{l}\text { JARAMILLO VÁZQUEZ, } \\
\text { Alejandra }\end{array}$ & 2005 & $\begin{array}{l}\text { El museo interactivo como espacio } \\
\text { de comunicación e interacción: } \\
\text { aproximaciones desde un estudio } \\
\text { de recepción. }\end{array}$ & $\begin{array}{l}\text { Guillermo } \\
\text { Orozco } \\
\text { Gómez }\end{array}$ \\
\hline
\end{tabular}




\begin{tabular}{|c|c|c|c|}
\hline Autor & Año & Título & Asesor \\
\hline $\begin{array}{l}\text { GÓMEZ GUTIÉRREZ, } \\
\text { Claudia Iris }\end{array}$ & 2005 & $\begin{array}{l}\text { Cartografía de las telenovelas: } \\
\text { por la ruta de la realidad de TV } \\
\text { Azteca. }\end{array}$ & $\begin{array}{l}\text { Raúl Fuentes } \\
\text { Navarro }\end{array}$ \\
\hline $\begin{array}{l}\text { MUÑOZ DELGADO, } \\
\text { José }\end{array}$ & 2005 & $\begin{array}{l}\text { Hipertextos matemáticos para } \\
\text { cibernautas adolescentes. Apuntes } \\
\text { para un diseño desde la comuni- } \\
\text { cación. }\end{array}$ & $\begin{array}{l}\text { Raúl Fuentes } \\
\text { Navarro }\end{array}$ \\
\hline $\begin{array}{l}\text { PONCE DE LEÓN } \\
\text { FONZ, Ignacio }\end{array}$ & 2005 & $\begin{array}{l}\text { Chapalita y sus transformaciones: } \\
\text { procesos de comunicación y for- } \\
\text { mas urbanas. }\end{array}$ & $\begin{array}{l}\text { Rossana } \\
\text { Reguillo Cruz }\end{array}$ \\
\hline
\end{tabular}

UNIVERSIDAD DE GUADALAJARA

\begin{tabular}{|c|c|c|c|}
\hline Autor & Año & Título & Asesor \\
\hline $\begin{array}{l}\text { CORTÁZAR } \\
\text { RODRÍGUEZ, } \\
\text { Francisco } \\
\text { (ciencias } \\
\text { sociales) }\end{array}$ & 1998 & $\begin{array}{l}\text { Telemática, cambios y relaciones } \\
\text { sociales. Estudio sobre los usos de las } \\
\text { tecnologías informáticas y comunica- } \\
\text { cionales en el trabajo. }\end{array}$ & $\begin{array}{l}\text { Raúl Fuentes } \\
\text { Navarro }\end{array}$ \\
\hline $\begin{array}{l}\text { RODRÍGUEZ } \\
\text { SALAZAR, Tania } \\
\text { (CS) }\end{array}$ & 1998 & $\begin{array}{l}\text { La reproducción cotidiana del matri- } \\
\text { monio. Representaciones, relatos de } \\
\text { vida y sociedad. }\end{array}$ & $\begin{array}{l}\text { Cecilia } \\
\text { Cervantes } \\
\text { Barba }\end{array}$ \\
\hline $\begin{array}{l}\text { PALENCIA VILLA, } \\
\text { Ma. de las } \\
\text { Mercedes (CS) }\end{array}$ & 1998 & $\begin{array}{l}\text { Construcción de la identidad de género } \\
\text { en las educadoras. }\end{array}$ & $\begin{array}{l}\text { Fernando Leal } \\
\text { Carretero }\end{array}$ \\
\hline $\begin{array}{l}\text { GARZA CUÉLLAR, } \\
\text { Margarita Rosa } \\
\text { (CS) }\end{array}$ & 2000 & $\begin{array}{l}\text { Organizaciones tradicionales VS te- } \\
\text { levisión: el caso de la Alianza Fuerza } \\
\text { de Opinión Pública y su lucha por la } \\
\text { moralización del espacio público. }\end{array}$ & $\begin{array}{l}\text { A. Renée } \\
\text { de la Torre } \\
\text { Castellanos }\end{array}$ \\
\hline $\begin{array}{l}\text { PALÁU CARDONA, } \\
\text { María Magdalena } \\
\text { Sofía }(\mathrm{CS})\end{array}$ & 2001 & $\begin{array}{l}\text { Representaciones y metáforas. Un } \\
\text { acercamiento exploratorio a la dimen- } \\
\text { sión simbólica de las instituciones. }\end{array}$ & $\begin{array}{l}\text { Cecilia } \\
\text { Cervantes } \\
\text { Barba }\end{array}$ \\
\hline $\begin{array}{l}\text { ÁLVAREZ } \\
\text { RODRÍGUEZ, } \\
\text { Mónica (CS) }\end{array}$ & 2001 & $\begin{array}{l}\text { La producción de la nota roja en Gua- } \\
\text { dalajara. }\end{array}$ & $\begin{array}{l}\text { María Elena } \\
\text { Hernández } \\
\text { Ramírez }\end{array}$ \\
\hline
\end{tabular}




\begin{tabular}{|c|c|c|c|}
\hline Autor & Año & Título & Asesor \\
\hline $\begin{array}{l}\text { RIVERA ORRACA, } \\
\text { Lorena (CS) }\end{array}$ & 2001 & $\begin{array}{l}\text { Jóvenes, identidades y espacios cultu- } \\
\text { rales. El caso del Tianguis Cultural de } \\
\text { Guadalajara. }\end{array}$ & $\begin{array}{l}\text { Rossana } \\
\text { Reguillo Cruz }\end{array}$ \\
\hline $\begin{array}{l}\text { MORQUECHO } \\
\text { GÜITRÓN, Ana } \\
\text { Cecilia (CS) }\end{array}$ & 2002 & $\begin{array}{l}\text { Representaciones del trabajo del po- } \\
\text { licía auxiliar: sus prácticas y su vida } \\
\text { cotidiana. }\end{array}$ & $\begin{array}{l}\text { Cecilia } \\
\text { Cervantes } \\
\text { Barba }\end{array}$ \\
\hline $\begin{array}{l}\text { HERNÁNDEZ } \\
\text { TAPIA, Emma del } \\
\text { Rocío }\end{array}$ & 2002 & $\begin{array}{l}\text { La dinámica comunicativa en la inte- } \\
\text { racción grupos ciudadanos- medios de } \\
\text { comunicación. }\end{array}$ & $\begin{array}{l}\text { Francisco } \\
\text { de J. Aceves } \\
\text { González }\end{array}$ \\
\hline $\begin{array}{l}\text { BECERRA } \\
\text { SÁNCHEZ, Ma. } \\
\text { Guadalupe }\end{array}$ & 2002 & $\begin{array}{l}\text { Computadoras y educación. Repre- } \\
\text { sentaciones sociales de los maestros } \\
\text { acerca del uso de la computadora en } \\
\text { la docencia. }\end{array}$ & $\begin{array}{l}\text { Guillermo } \\
\text { Orozco Gómez }\end{array}$ \\
\hline $\begin{array}{l}\text { PADILLA DE LA } \\
\text { TORRE, María } \\
\text { Rebeca }\end{array}$ & 2002 & $\begin{array}{l}\text { Telenovelas e identidad de género. } \\
\text { Un análisis entre familias aguascalen- } \\
\text { tenses. }\end{array}$ & $\begin{array}{l}\text { Guillermo } \\
\text { Orozco Gómez }\end{array}$ \\
\hline $\begin{array}{l}\text { DE LEÓN } \\
\text { VÁZQUEZ, } \\
\text { Salvador }\end{array}$ & 2002 & $\begin{array}{l}\text { La producción de noticias en Aguasca- } \\
\text { lientes: cómo se construye el acontecer } \\
\text { periodístico. } \\
\text { (PREMIO NACIONAL CONEICC 2002). }\end{array}$ & $\begin{array}{l}\text { María Elena } \\
\text { Hernández } \\
\text { Ramírez }\end{array}$ \\
\hline $\begin{array}{l}\text { GÓMEZ } \\
\text { RODRÍGUEZ, } \\
\text { Gabriela (CS) }\end{array}$ & 2002 & $\begin{array}{l}\text { El reality show como constructo de la } \\
\text { realidad social local: el caso de Ciudad } \\
\text { Desnuda Jalisco. }\end{array}$ & $\begin{array}{l}\text { Martha Renero } \\
\text { Quintanar }\end{array}$ \\
\hline $\begin{array}{l}\text { MORA ROSAS, } \\
\text { José Manuel }\end{array}$ & 2002 & $\begin{array}{l}\text { Oferta esotérica en Guadalajara: una } \\
\text { visión sociosemiótica. }\end{array}$ & $\begin{array}{l}\text { A. Renée } \\
\text { de la Torre } \\
\text { Castellanos }\end{array}$ \\
\hline $\begin{array}{l}\text { DELGADO PÉREZ, } \\
\text { Juan Pedro }\end{array}$ & 2003 & $\begin{array}{l}\text { Representación y praxis de la revista } \\
\text { literaria independiente en México. }\end{array}$ & $\begin{array}{l}\text { Celia del } \\
\text { Palacio Montiel }\end{array}$ \\
\hline $\begin{array}{l}\text { FONSECA } \\
\text { ÁVALOS, Mayra } \\
\text { Elena }\end{array}$ & 2003 & $\begin{array}{l}\text { De lo tradicional a lo moderno. Activi- } \\
\text { dades de tiempo libre en El Correo de } \\
\text { la Tarde, } 1891-1900 .\end{array}$ & $\begin{array}{l}\text { Celia del } \\
\text { Palacio Montiel }\end{array}$ \\
\hline $\begin{array}{l}\text { GONZÁLEZ } \\
\text { PÉREZ, Teresa de } \\
\text { Jesús }\end{array}$ & 2003 & $\begin{array}{l}\text { Redes de comunicación académica. } \\
\text { Estudio de caso en los campos de co- } \\
\text { municación, química y psicología de la } \\
\text { Universidad de Guadalajara. }\end{array}$ & $\begin{array}{l}\text { Enrique E. } \\
\text { Sánchez Ruiz }\end{array}$ \\
\hline
\end{tabular}




\begin{tabular}{|c|c|c|c|}
\hline Autor & Año & Título & Asesor \\
\hline RODRÍGUEZ & \multirow[t]{3}{*}{2003} & Las ferias internacionales de libro & Francisco \\
\hline CHÁVEZ, Hugo & & como industrias culturales. FIL-Guada- & Hernández \\
\hline Concepción (CS) & & lajara, estudio de caso. & Lomelí \\
\hline MARTÍNEZ & \multirow[t]{4}{*}{2003} & Ojos que no ven... Fotoperiodismo en & María Elena \\
\hline Moscoso, & & Guadalajara. Valores noticiosos en la & Hernández \\
\hline Dolores Marisa & & producción de la nota fotográfica en $E l$ & Ramírez \\
\hline & & Informador, Público y Mural. & \\
\hline SARRACINO & \multirow[t]{2}{*}{2003} & Elementos democráticos en el diario $\mathrm{El}$ & María Elena \\
\hline RAMÍREZ, Edith & & $\begin{array}{l}\text { Imparcial, actor político y mediatiza- } \\
\text { dor de los discursos en la precampaña } \\
\text { para la gubernatura de Sonora en el } \\
2003 \text {. }\end{array}$ & $\begin{array}{l}\text { Hernández } \\
\text { Ramírez }\end{array}$ \\
\hline GARCÍA GÓMEZ, & \multirow[t]{3}{*}{2003} & Las relaciones entre los reporteros & María Elena \\
\hline Rosa Eugenia & & y los funcionarios de las fuentes de & Hernández \\
\hline (CS) & & $\begin{array}{l}\text { información de la zona metropolitana } \\
\text { de Guadalajara. }\end{array}$ & Ramírez \\
\hline MANCILLA & \multirow[t]{3}{*}{2003} & El discurso político del Cardenal Juan & A. Renée \\
\hline VALDEZ, & & Sandoval Íñiguez en la prensa escrita & de la Torre \\
\hline Esmeralda (CS) & & de Guadalajara (1994-2001) & Castellanos \\
\hline VIZCARRA & \multirow[t]{3}{*}{2003} & El discurso de la modernidad en Blade & Sarah Corona \\
\hline SCHUMM, Juan & & Runner. Un enfoque sociocultural. & Berkin \\
\hline Fernando & & & \\
\hline ROBLES & \multirow[t]{2}{*}{2003} & Mensajes televisivos y discurso infantil & Sarah Corona \\
\hline IRAZOQUI, Yadira & & $\begin{array}{l}\text { sobre desigualdades sociales en dos } \\
\text { grupos sociales de la zona metropolita- } \\
\text { na de Guadalajara. }\end{array}$ & Berkin \\
\hline $\begin{array}{l}\text { CAMACHO MEZA, } \\
\text { Jesús Ernesto }\end{array}$ & 2004 & $\begin{array}{l}\text { La socialización política de los jóvenes } \\
\text { de Culiacán, Sinaloa. El papel del } \\
\text { periódico y la televisión en su incorpo- } \\
\text { ración política partidista. }\end{array}$ & $\begin{array}{l}\text { Armando M. } \\
\text { Ibarra López }\end{array}$ \\
\hline $\begin{array}{l}\text { BARRÓN PÉREZ, } \\
\text { Gabriel }\end{array}$ & 2004 & $\begin{array}{l}\text { Hacia una teoría del espacio comu- } \\
\text { nicativo: una lectura ontológica de la } \\
\text { acción comunicativa. }\end{array}$ & $\begin{array}{l}\text { Armando } \\
\text { Zacarías } \\
\text { Castillo }\end{array}$ \\
\hline
\end{tabular}




\begin{tabular}{|c|c|c|c|}
\hline Autor & Año & Título & Asesor \\
\hline $\begin{array}{l}\text { CORONADO } \\
\text { PONCE, Alán } \\
\text { René }\end{array}$ & 2004 & $\begin{array}{l}\text { La radiodifusión familiar en México y } \\
\text { su inserción en la dinámica de concen- } \\
\text { tración de medios: un estudio de caso } \\
\text { en Guadalajara. }\end{array}$ & $\begin{array}{l}\text { Enrique E. } \\
\text { Sánchez Ruiz }\end{array}$ \\
\hline $\begin{array}{l}\text { GUTIÉRREZ } \\
\text { CAMACHO, } \\
\text { Clemencia }\end{array}$ & 2004 & $\begin{array}{l}\text { La oferta televisiva desigual en la } \\
\text { globalización: implicaciones para la } \\
\text { televisión abierta y de pago en Jalisco. }\end{array}$ & $\begin{array}{l}\text { Enrique E. } \\
\text { Sánchez Ruiz }\end{array}$ \\
\hline $\begin{array}{l}\text { MACÍAS } \\
\text { RODRÍGUEZ, } \\
\text { Héctor Jaime (CS) }\end{array}$ & 2004 & $\begin{array}{l}\text { La prensa de Guadalajara y el proceso } \\
\text { electoral Jalisco 2000: análisis del } \\
\text { segundo nivel de agenda en la confor- } \\
\text { mación de imágenes de los candidatos } \\
\text { a gobernador en los lectores del perió- } \\
\text { dico Público. }\end{array}$ & $\begin{array}{l}\text { Francisco } \\
\text { de J. Aceves } \\
\text { González }\end{array}$ \\
\hline $\begin{array}{l}\text { HERNÁNDEZ } \\
\text { LUGAY, Lindsay } \\
\text { Priscila }\end{array}$ & 2004 & $\begin{array}{l}\text { Comunicación académica en Internet: } \\
\text { hacia la apropiación de revistas de } \\
\text { comunicación electrónicas por los } \\
\text { investigadores de la comunicación en } \\
\text { México. }\end{array}$ & $\begin{array}{l}\text { Francisco } \\
\text { Hernández } \\
\text { Lomelí }\end{array}$ \\
\hline $\begin{array}{l}\text { VILLALOBOS } \\
\text { CASTILLO, María }\end{array}$ & 2004 & $\begin{array}{l}\text { La imagen de Pablo Salazar a través } \\
\text { del análisis del discurso periodístico de }\end{array}$ & $\begin{array}{l}\text { Francisco } \\
\text { Hernández }\end{array}$ \\
\hline $\begin{array}{l}\text { Eliazú } \\
\text { CORVERA } \\
\text { SÁNCHEZ, } \\
\text { Alejandro } \\
\text { Antonio }\end{array}$ & 2004 & $\begin{array}{l}\text { El Cuarto Poder y La Voz del Sureste. } \\
\text { Adolescentes e internet. Usos educa- } \\
\text { tivos del medio entre estudiantes de } \\
\text { educación media básica. }\end{array}$ & $\begin{array}{l}\text { Lomelí } \\
\text { Guillermo } \\
\text { Orozco Gómez }\end{array}$ \\
\hline $\begin{array}{l}\text { LÓPEZ GARCÍA, } \\
\text { Verónica }\end{array}$ & 2004 & $\begin{array}{l}\text { La tercera generación de derechos } \\
\text { humanos en el discurso de opinión } \\
\text { sobre la guerra de Irak en la prensa de } \\
\text { Guadalajara. }\end{array}$ & $\begin{array}{l}\text { María Elena } \\
\text { Hernández } \\
\text { Ramírez }\end{array}$ \\
\hline $\begin{array}{l}\text { RAMOS } \\
\text { GONZÁLEZ, } \\
\text { Mario Alberto }\end{array}$ & 2004 & $\begin{array}{l}\text { La figura presidencial en la prensa es- } \\
\text { crita en el contexto de la transición a la } \\
\text { democracia en México. El discurso de } \\
\text { La Jornada y Excélsior, 1988-2000. }\end{array}$ & $\begin{array}{l}\text { Pablo } \\
\text { Arredondo } \\
\text { Ramírez }\end{array}$ \\
\hline
\end{tabular}




\begin{tabular}{|c|c|c|c|}
\hline Autor & Año & Título & Asesor \\
\hline $\begin{array}{l}\text { TORRES } \\
\text { RAMÍREZ, } \\
\text { Gustavo Rubén }\end{array}$ & 2004 & $\begin{array}{l}\text { Vivir e imaginar la ciudad. Tijuana: } \\
\text { imaginarios urbanos de una ciudad } \\
\text { fronteriza. }\end{array}$ & $\begin{array}{l}\text { Patricia Safa } \\
\text { Barraza }\end{array}$ \\
\hline $\begin{array}{l}\text { RUIZ SOLÍs, } \\
\text { Rosalba }\end{array}$ & 2004 & $\begin{array}{l}\text { Construcciones sociales de los y las } \\
\text { adolescentes sobre los efectos de los } \\
\text { mensajes preventivos del consumo de } \\
\text { drogas ilegales transmitidos a través de } \\
\text { la televisión. }\end{array}$ & $\begin{array}{l}\text { Ramiro } \\
\text { Caballero } \\
\text { Hoyos }\end{array}$ \\
\hline $\begin{array}{l}\text { PRECIADO } \\
\text { NÚÑEZ, María } \\
\text { Cristina }\end{array}$ & 2004 & $\begin{array}{l}\text { La enseñanza del español en los libros } \\
\text { de texto gratuitos de lecturas y activi- } \\
\text { dades para el primer ciclo escolar. Una } \\
\text { aproximación discursiva. }\end{array}$ & $\begin{array}{l}\text { Sarah Corona } \\
\text { Berkin }\end{array}$ \\
\hline $\begin{array}{l}\text { PÉREZ DANIEL, } \\
\text { Myriam Rebeca }\end{array}$ & 2004 & $\begin{array}{l}\text { El discurso y el saber amoroso: figuras } \\
\text { y tópicas sobre el amor en epístolas } \\
\text { juveniles zamoranas. }\end{array}$ & $\begin{array}{l}\text { Tania } \\
\text { Rodríguez } \\
\text { Salazar }\end{array}$ \\
\hline $\begin{array}{l}\text { LANDEROS } \\
\text { CASILLAS, Martha } \\
\text { Ileana }\end{array}$ & 2005 & $\begin{array}{l}\text { Acercamiento al campo de la media- } \\
\text { ción televisiva y la educación artística } \\
\text { en dos escuelas de la zona metropolita- } \\
\text { na de Guadalajara. }\end{array}$ & $\begin{array}{l}\text { Armando M. } \\
\text { Ibarra López }\end{array}$ \\
\hline $\begin{array}{l}\text { PINEDA } \\
\text { TRUJILLO, Rosa } \\
\text { María (CS) }\end{array}$ & 2005 & $\begin{array}{l}\text { Significados circulando: consumo de } \\
\text { medios impresos y televisivos por jó- } \\
\text { venes preparatorianos de Guadalajara. }\end{array}$ & $\begin{array}{l}\text { Armando M. } \\
\text { Ibarra López }\end{array}$ \\
\hline $\begin{array}{l}\text { MONTUFAR } \\
\text { SERRANO, } \\
\text { Rosangel Ariadna }\end{array}$ & 2005 & $\begin{array}{l}\text { La construcción de la imagen pública } \\
\text { de los candidatos presidenciales en el } \\
\text { proceso electoral de } 2000 \text { en los noti- } \\
\text { cieros El Noticiero y Hechos. }\end{array}$ & $\begin{array}{l}\text { Francisco } \\
\text { de J. Aceves } \\
\text { González }\end{array}$ \\
\hline
\end{tabular}

